
\title{
(1)
}

\section{Oriented Zinc Oxide Nanocrystalline Thin Films Grown from Sol-Gel Solution}

\author{
Jyotshna Pokharel ${ }^{1}$, Maheshwar Shrestha ${ }^{1}$, Li Qin Zhou ${ }^{2,3}$, Victor Neto ${ }^{2,3, *}$ and Qi Hua Fan ${ }^{1, *}$ \\ ${ }^{1}$ Department of Electrical Engineering and Computer Science, South Dakota State University, Brooking, SD 57007, USA \\ ${ }^{2}$ Centre for Mechanical Technology and Automation, Department of Mechanical Engineering, University of Aveiro, 3810-193 \\ Aveiro, Portugal \\ ${ }^{3}$ Aveiro Nanotechnology Institute, University of Aveiro, 3810-193 Aveiro, Portugal
}

\begin{abstract}
Zinc oxide $(\mathrm{ZnO})$ is a wide band gap $(\sim 3.37 \mathrm{eV})$ semiconductor. Thin film $\mathrm{ZnO}$ has many attractive applications in optoelectronics and sensors. Recently, nanostructured $\mathrm{ZnO}$ (e.g. $\mathrm{ZnO}$ quantum dot) has been demonstrated as a hyperbolic material; its dielectric function has opposite signs along different crystal axes within the mid-infrared, making it an interesting material for metamaterials and nanophotonics. Conventional sputtering deposition usually leads to the formation of polycrystalline $\mathrm{ZnO}$ films with randomly oriented grains and rough surface. This work demonstrated a solution-based process to grow $\mathrm{ZnO}$ thin films with highly oriented nanocrystals. Low-temperature plasmas were employed to modulate the microstructure and optical properties of the films. Such highly anisotropic nanostructured transparent semiconductor films may lead to interesting material properties in developing new optoelectronic devices.
\end{abstract}

Received on 21-05-2015 Accepted on 12-08-2015 Published on 14-09-2015

Keywords: Zinc oxide, sol-gel, oxygen plasma, crystal size.

\section{INTRODUCTION}

Zinc oxide $(\mathrm{ZnO})$ is a II-VI compound semiconductor with wide band gap $\sim 3.37 \mathrm{eV}[1,2]$. Thin film $\mathrm{ZnO}$ is highly transparent in the visible spectrum $(>90 \%)$, with moderate Hall mobility ranging from 0.2 to $7 \mathrm{~cm}^{2} \mathrm{~V}^{-1} \mathrm{~s}^{-1}$. These characteristics combined with other interesting properties, such as a strong blue luminescence and a large acoustic velocity $(6336 \mathrm{~m} / \mathrm{s})$, make $\mathrm{ZnO}$ attractive for use in many applications. Owing to their better stability than indium tin oxide in hydrogen plasma, $\mathrm{ZnO}$ thin films have been used in the fabrication of hydrogenated amorphous silicon solar cells $[3,4]$. $\mathrm{ZnO}$ has also been used as transparent electrodes in displays and piezoelectric devices [5-7]. Wide band gap $\mathrm{ZnO}$ is a potential material for shortwavelength optoelectronic devices, such as UV lasers, blue to UV lightemitting diodes and UV detectors [8,9], which can be applied to high density data storage systems, solid-state lighting, secure communications and bio-detection. Of particularly interesting, $\mathrm{ZnO}$ nanostructures (e.g. $\mathrm{ZnO}$ quantum dots) have been

"Department of Electrical Engineering and Computer Science, South Dakota State University, Brooking, SD 57007, USA; Tel: 605-688-5910;

Fax: 605-688-4401; E-mail: qihua.fan@sdstate.edu

Centre for Mechanical Technology and Automation, Department of Mechanical Engineering, University of Aveiro, 3810-193 Aveiro, Portugal;

E-mail: vneto@ua.pt demonstrated as a hyperbolic material; its dielectric function has opposite signs along different crystal axes within the midinfrared, making it an attractive metamaterial and promising for nanophotonics [10].

The wurtzite crystal structure of $\mathrm{ZnO}$ is thermodynamically stable with oxygen atoms on hexagonal sites and zinc atoms on tetrahedral sites [11]. It exists with non-polar (1011) surface termination, polar (0001) O-termination, and polar (0001) Zn-terminated surfaces [12], resulting in terminationdependent chemical reactivity. $\mathrm{ZnO}$ crystallites with preferential orientation are desirable for applications where crystallographic anisotropy is a prerequisite as in UV-diode, piezoelectric surface acoustic wave or acousto-optic devices [13].

Various methods have been used to fabricate $\mathrm{ZnO}$ films. The common methods include pulsed laser deposition, RF magnetron sputtering, chemical vapor deposition, and spray pyrolysis [14, 15]. Polycrystalline $\mathrm{ZnO}$ films fabricated from these processes usually consist of randomly oriented crystals. Furthermore, vacuum-based processes are generally expensive.

Solution-based sol-gel method offers simple, easy and lowcost deposition of $\mathrm{ZnO}$, which can be integrated into roll-to- 
roll fabrication [16-18]. ZnO films prepared by solution processes usually have high resistivity. Post annealing at moderate temperatures in a proper environment is needed to reduce the resistivity.

This work aims to produce nanostructured $\mathrm{ZnO}$ thin films with highly oriented crystals using a solution-based process. As discussed above, such films may find a broad variety of applications. Post plasma treatment is employed to verify whether or not it can modulate the film structures and optical properties at low temperatures.

\section{EXPERIMENTAL PROCEDURE}

$\mathrm{ZnO}$ nanostructured thin films were deposited by sol-gel spin coating onto glass substrate. Zinc acetate $\left[\mathrm{Zn}\left(\mathrm{CH}_{3} \mathrm{COO}\right)\right.$ $2 \mathrm{H}_{2} \mathrm{O}$ ],2-methoxethanol (MEA), and ethanolamine were used as the starting material, solvent, and stabilizer, respectively. The molar ratio of MEA to zinc acetate dehydrate was maintained at 1.0 and the concentration of zinc acetate was $0.35 \mathrm{M}$. The solution was stirred at $500 \mathrm{RPM}$ for two hours at room temperature followed by stirring at $80^{\circ} \mathrm{C}$ for $1 \mathrm{hr}$ to result in a clear homogeneous solution. The glass substrates were cleaned with a soapy water, DI water, acetone and IPA in sequence using a Fisher Scientific FS60D ultrasonic cleaner, each step for $10 \mathrm{~min}$, respectively. The zinc oxide solution was then spin-coated on the glass substrates at 2500 RPM for 30 seconds using a LAURELL WS-650MH23NPP/LITE spin coater. After the deposition, the film was dried at different temperatures from $200^{\circ} \mathrm{C}$ to $500^{\circ} \mathrm{C}$ for 1 hour in a furnace to remove organic residuals. The routine was repeated from coating to drying for five times to give a final film thickness $\sim 200 \mathrm{~nm}$.

After the films were deposited, the samples were processed with oxygen plasma generated with a capacitively coupled RF discharge, during which the oxygen gas pressure was maintained at $\sim 2$ Torr. No external heating was applied and the substrate temperature was below $150^{\circ} \mathrm{C}$ during the plasma treatment. The thickness of the film was measured using VEECO DEKTAK 150 surface profiler. The transmittance measurement was carried out using FILMETRICS F20-UVX spectrophotometer. X-ray diffraction (XRD) was taken using RIGAKU SMARTLAB system.

\section{RESULTS AND DISCUSSION}

The transmission spectra of the $\mathrm{ZnO}$ films fabricated at different temperatures are shown in Figure 1. The $\mathrm{ZnO}$ film prepared at $200^{\circ} \mathrm{C}$ showed good transmittance in $380-750 \mathrm{~nm}$ range with an average transmittance above $90 \%$. Increasingthe temperature from $200^{\circ} \mathrm{C}$ to $400^{\circ} \mathrm{C}$, the transmittance increased slightly. The maximum point of transmittance shifted to shorter wavelength with the increase in the temperature, indicating that the film optical thickness was reduced. This was due to the removal of organic residuals at higher temperatures. Further increase the fabrication temperature to $500^{\circ} \mathrm{C}$ led to decrease in the transmittance. Two possible reasons contributed to this reduction in transparency: surface roughening that led to light scattering and oxygen loss that created vacancies at hightemperatures. Similar reduction in optical transparency was observed when the annealing temperature of $\mathrm{ZnO}$ films was increased [19].

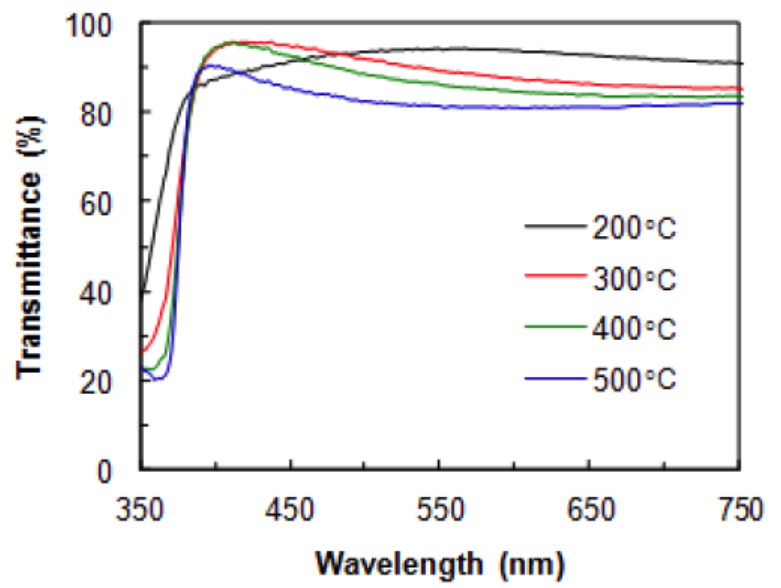

Figure 1: Optical transmittance spectra of $\mathrm{ZnO}$ films prepared at different temperature.

Figure 2 shows the XRD pattern of the $\mathrm{ZnO}$ films prepared at different temperatures. The $\mathrm{ZnO}$ films prepared at temperatures above $400^{\circ} \mathrm{Cshowed}$ oriented crystal growth along (002) plane. This oriented growth confirmed that the highest density of $\mathrm{Zn}$ atoms was in the (002) planes as it was kinetically favorable [20]. At sufficient temperatures, the excess energy acquired by the $\mathrm{ZnO}$ crystallites allowed them to orient themselves along the (002) plane where the surface energy was minimum [19]. The $\mathrm{ZnO}$ films prepared at temperatures below $300^{\circ} \mathrm{C}$ did not exhibit obvious crystallization. The films weremostly amorphous. An increase in the (002) peak intensity was observed when the films were prepared at $300^{\circ} \mathrm{C}, 400^{\circ} \mathrm{C}$, and $500^{\circ} \mathrm{C}$, as shown in Figure 2. The gain in peak intensity was obviously due to an increase in the crystallinity with temperature.

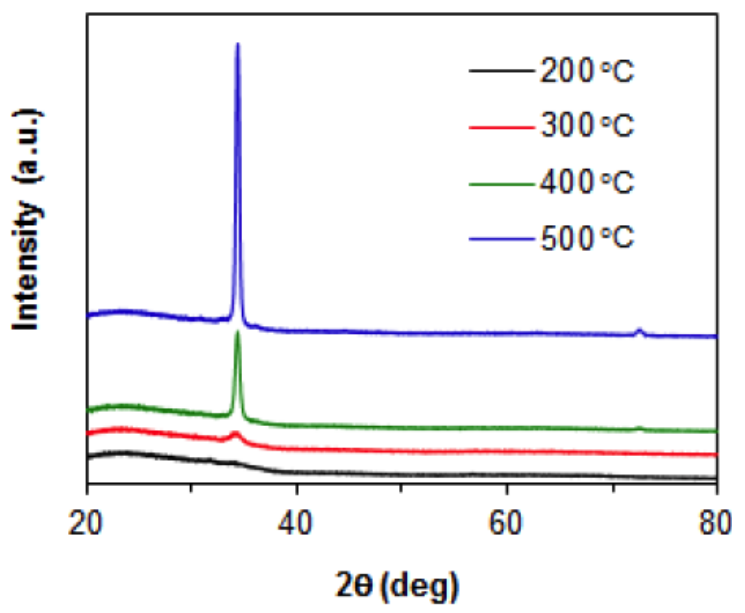

Figure 2: XRD patterns of $\mathrm{ZnO}$ films prepared at different temperatures. 
Figure 3 shows the effect of temperature on the crystal size of the $\mathrm{ZnO}$ films. The average crystal size increased with the process temperature. The size of crystallite was estimated from the full-width at half-maximum (FWHM) of (002) peak using the Scherrer formula [21],

$$
d=\frac{0.9 \lambda}{B \cos \theta_{B}},
$$

where $\lambda$ is the X-ray wavelength of $1.54 \AA, \theta_{B}$ is Bragg diffraction angle, and $B$ is the FWHM of the XRD diffraction peak. The crystal size increased from $5.9 \mathrm{~nm}$ at $300^{\circ} \mathrm{C}$ to $23.8 \mathrm{~nm}$ at $500^{\circ} \mathrm{C}$. The increase in the temperature caused coalescence/merging of small grains by grain boundary diffusion, resulting in grain growth [22].

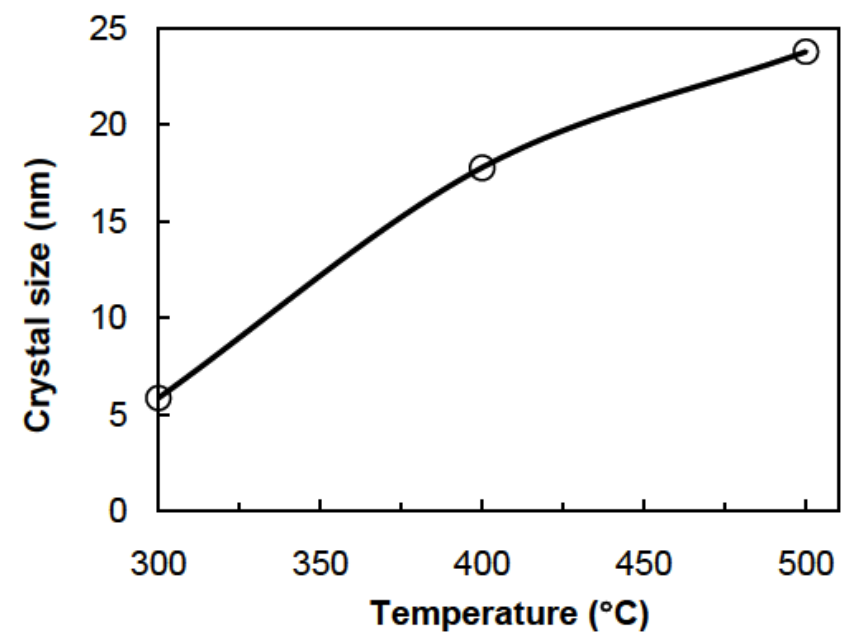

Figure 3: Effect of temperature on the crystal size of the $\mathrm{ZnO}$ films.

Figure $\mathbf{4}$ compares the optical transmittance of the $\mathrm{ZnO}$ films prepared at $500^{\circ} \mathrm{C}$ followed by oxygen plasma treatment for $5,10,20$ and 40 minutes. Overall, the transmittance slightly increased after the plasma treatment. 20-minute oxygen plasma treatment appeared sufficient, while prolonged

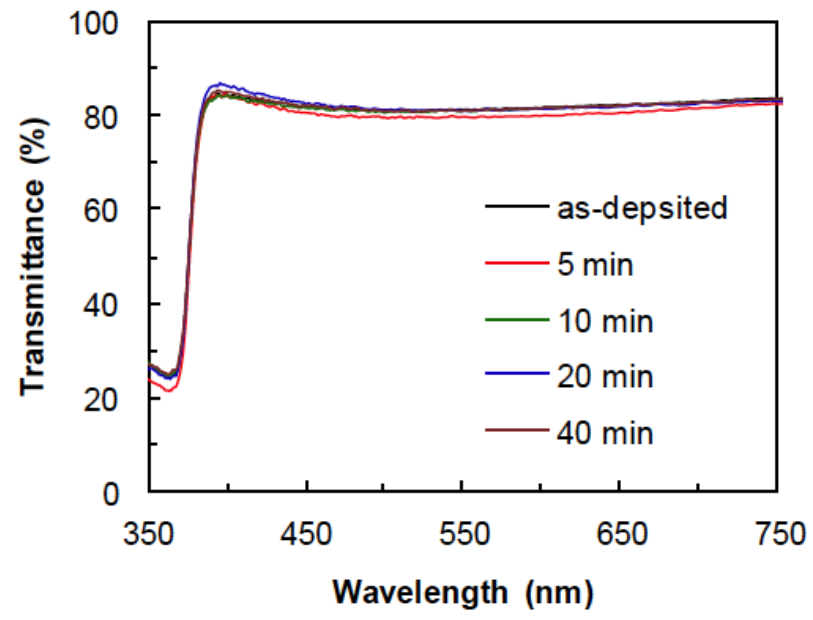

Figure 4: Comparison of optical transmission spectra of $\mathrm{ZnO}$ films processed at $500^{\circ} \mathrm{C}$ followed by oxygen plasma treatment for different times. plasma treatment (e.g. 40 minutes) led to slight decreasein the transmittance. The variation in the transmittance with the plasma treatment time was attributed to two opposite effects: 1) oxygen plasma reduced oxygen vacancies and led to the increase in the transmittance; and 2) the bombardment of charged ions on the $\mathrm{ZnO}$ film created defects and roughened the film surface, leading to a decrease in the transmittance.

Figure 5 compares XRD spectra of the $\mathrm{ZnO}$ films processed at $500^{\circ} \mathrm{C}$ followed by oxygen plasma treatment for $5,10,20$ and 40 minutes. The FWHM values for the XRD spectra are presented in Table 1. The FWHM value for the as-deposited $\mathrm{ZnO}$ film was 0.3639 , while the lowest FWHM value was obtained for $20 \mathrm{~min} \mathrm{O}_{2}$ plasma treatment. However, sharpening of the diffraction peak or lowering of the FWHM value was not seen inthe films exposed to $\mathrm{O}_{2}$ plasma beyond 20 minutes. This result was further supported by analyzing the crystal size of the $\mathrm{ZnO}$ films treated by $\mathrm{O}_{2}$ plasma for different time.

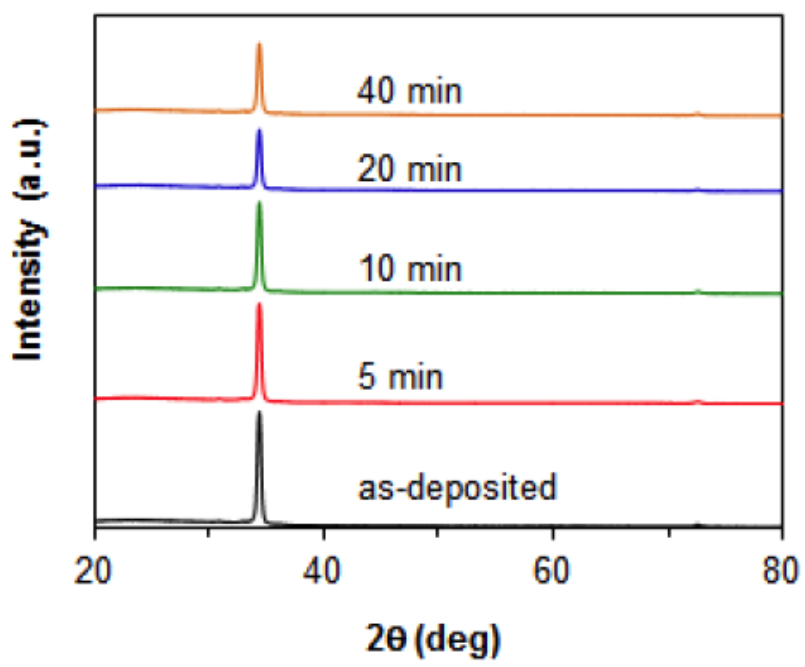

Figure 5: Comparison of XRD spectra of $\mathrm{ZnO}$ films processed at $500^{\circ} \mathrm{C}$ followed by oxygen plasma treatment for different times.

Table 1: FWHM of XRD (002) Peak for the ZnO Films Treated with $\mathrm{O}_{2}$ Plasma

\begin{tabular}{|c|c|}
\hline $\mathbf{O}_{2}$ Plasma Treatment & FWHM \\
\hline \hline As-deposited & 0.3639 \\
\hline $5 \mathrm{~min}$ & 0.3585 \\
\hline $10 \mathrm{~min}$ & 0.3603 \\
\hline $20 \mathrm{~min}$ & 0.3567 \\
\hline $40 \mathrm{~min}$ & 0.3652 \\
\hline
\end{tabular}

Figure 6 shows the crystal size of the ZnO films treated by oxygen plasma. The average crystal size increased slightly with plasma treatment time till 20 minutes, after which thecrystal size decreased. The crystal size increased from $23.80 \mathrm{~nm}$ (as-deposited) to $24.35 \mathrm{~nm}$ (20-minute oxygen 
plasma). The crystal size after 40-minute oxygen plasma treatment dropped to $23.77 \mathrm{~nm}$.

These results indicated that oxygen plasma treatment increased the crystallinity of the $\mathrm{ZnO}$ films by increasing the size of the crystallites. An optimum treatment time was 20 minutes. This result was in agreement with the transmittance variation.As discussed previously, this happened due to the diffusion of oxygen from the plasma into the $\mathrm{ZnO}$ film and reduced oxygen vacancies. However, further increase in oxygen plasma treatment time led to excessive ion bombardment, which broke $\mathrm{ZnO}$ bonds.

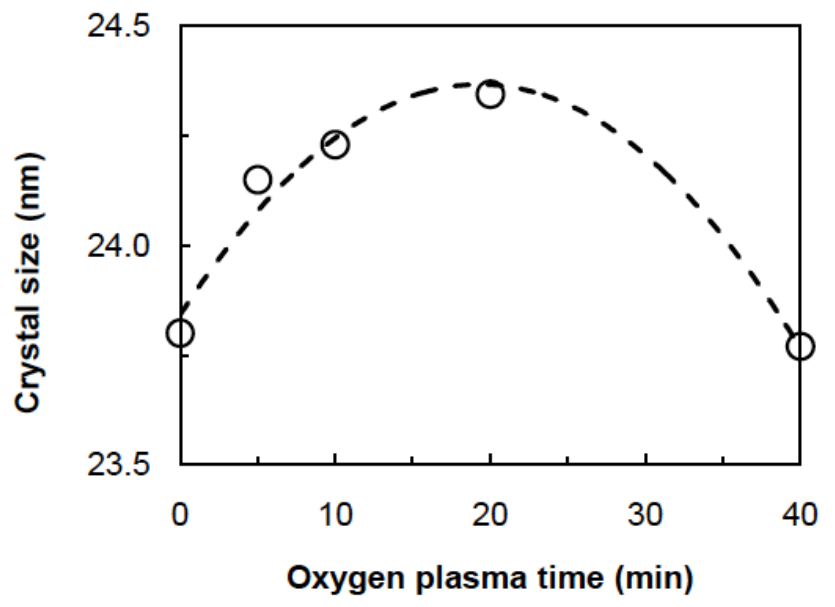

Figure 6: Effects of oxygen plasma treatment time on the crystal size of $\mathrm{ZnO}$ films.

\section{CONCLUSIONS}

Highly oriented (002) ZnO nanocrystalline thin films was produced by a solution-based process. The crystallinity of the $\mathrm{ZnO}$ films increased with the process temperature. The transmittance decreased slightly as the process temperature approached $500^{\circ} \mathrm{C}$. Oxygen plasma treatment led to increased transmittance. However, prolonged oxygen plasma treatmentled to reduced transmittance. The variation in the transmittance was in agreement with the change in the crystal size deduced from the FWHM of the XRD (002) peak.

\section{ACKNOWLEDGEMENTS}

This work was supported by the National Science Foundation, award CMMI-1462389. The authors also would like to thank the support from FCT Portugal Grant No. PTDC/CTM-CER/121440/2010 and PEst-C/EME/UI0481/ 2013.

\section{REFERENCES}

[1] Ilican S, Caglar $\mathrm{Y}$, Caglar M. Preparation and characterization of $\mathrm{ZnO}$ thin films deposited by sol-gel spin coating method. J Optoelectron Adv Mater 2008; 10: 2578-83.

[2] Meena JS, Chu M-C, Chang Y-C, et al. Effect of oxygen plasma on the surface states of $\mathrm{ZnO}$ films used to produce thin-film transistors on soft plastic sheets. J Mater Chem C 2013; 1: 6613-22. http://dx.doi.org/10.1039/c3tc31320d

[3] Li H, Wang J, Liu H, et al. Sol-gel preparation of transparent zinc oxide films with highly preferential crystal orientation. Vacuum 2004; 77: $57-62$.

http://dx.doi.org/10.1016/j.vacuum.2004.08.003

[4] Zhou Z, Kato K, Komaki T, et al. Effects of dopants and hydrogen on the electrical conductivity of ZnO. J Eur Ceram Soc 2004; 24: 139-46. http://dx.doi.org/10.1016/S0955-2219(03)00336-4

[5] Wang D, Zhao D, Wang F, Yao B, Shen D. Nitrogen-doped ZnO obtained by nitrogen plasma treatment. Physica Status Solidi A 2015 212: 846-50.

http://dx.doi.org/10.1002/pssa.201431779

[6] Van de Walle CG. Hydrogen as a cause of doping in zinc oxide. Phys Rev Lett 2000; 85: 1012.

http://dx.doi.org/10.1103/PhysRevLett.85.1012

[7] Kumar NS, Bangera KV, Shivakumar G. Effect of annealing on the properties of zinc oxide nanofiber thin films grown by spray pyrolysis technique. Appl Nanosci 2014; 4: 209-16.

http://dx.doi.org/10.1007/s13204-012-0190-9

[8] Ozgur U, Hofstetter D, Morkoc H. ZnO devices and applications: review of current status and future prospects. Proc IEEE 2010; 98 : 1255-68. http://dx.doi.org/10.1109/JPROC.2010.2044550

[9] Znaidi L. Sol-gel-deposited ZnO thin films: a review. Mater Sci Eng B 2010; 174: 18-30.

http://dx.doi.org/10.1016/i.mseb.2010.07.001

[10] Fonoberov VA, Balandin AA. Polar optical phonons in wurtzite spheroidal quantum dots: theory and application to $\mathrm{ZnO}$ and ZnO/MgZnO nanostructures. J Phys Condens Matter 2005; 17: 108597.

http://dx.doi.org/10.1088/0953-8984/17/7/003

[11] Hsu C-W, Cheng T-C, Yang C-H, Shen Y-L, Wu J-S, Wu S-Y. Effects of oxygen addition on physical properties of $\mathrm{ZnO}$ thin film grown by radio frequency reactive magnetron sputtering. J Alloys Compd 2011; 509: $1774-6$.

http://dx.doi.org/10.1016/j.jallcom.2010.10.037

[12] Kuo F-L, Li Y, Solomon M, Du J, Shepherd ND. Work function tuning of zinc oxide films by argon sputtering and oxygen plasma: An experimental and computational study. J Phys D Appl Phys 2012; 45: 065301.

http://dx.doi.org/10.1088/0022-3727/45/6/065301

[13] Znaidi L. Sol-gel-deposited $\mathrm{ZnO}$ thin films: a review. Materi Sci Eng B 2010; 174: 18-30.

http://dx.doi.org/10.1016/i.mseb.2010.07.001

[14] Elilarassi R, Chandrasekaran G. Effect of annealing on structural and optical properties of zinc oxide films. Mater Chem Phys 2010; 121 : 378-84.

http://dx.doi.org/10.1016/i.matchemphys.2010.01.053

[15] Ng Z-N, Chan K-Y, Sin Y-K, Hoon J-W, Ng S-S. Influence of postannealing condition on the properties of $\mathrm{ZnO}$ films. Ceram Int 2013; 39: S263-S7.

http://dx.doi.org/10.1016/j.ceramint.2012.10.074

[16] Sengupta J, Sahoo R, Mukherjee C. Effect of annealing on the structural, topographical and optical properties of sol-gel derived $\mathrm{ZnO}$ and AZO thin films. Mater Lett 2012; 83: 84-7.

http://dx.doi.org/10.1016/i.matlet.2012.05.130

[17] $\mathrm{Ng} Z-\mathrm{N}$, Chan $\mathrm{K}-\mathrm{Y}$, Tohsophon $\mathrm{T}$. Effects of annealing temperature on $\mathrm{ZnO}$ and $\mathrm{AZO}$ films prepared by sol-gel technique. Appl Surf Sci 2012; 258: 9604-9.

http://dx.doi.org/10.1016/j.apsusc.2012.05.156

[18] Zak AK, Abrishami ME, Majid WA, Yousefi R, Hosseini S. Effects of annealing temperature on some structural and optical properties of $\mathrm{ZnO}$ nanoparticles prepared by a modified sol-gel combustion method. Ceram Int 2011; 37: 393-8.

http://dx.doi.org/10.1016/j.ceramint.2010.08.017

[19] Sengupta J, Sahoo R, Bardhan K, Mukherjee C. Influence of annealing temperature on the structural, topographical and optical properties of sol-gel derived $\mathrm{ZnO}$ thin films. Mater Lett 2011; 65 : 2572-4.

http://dx.doi.org/10.1016/j.matlet.2011.06.021

[20] Zhai J, Zhang L, Yao X. The dielectric properties and optical propagation loss of $\mathrm{c}$-axis oriented $\mathrm{ZnO}$ thin films deposited by solgel process. Ceram Int 2000; 26: 883-5.

http://dx.doi.org/10.1016/S0272-8842(00)00031-6 
Journal of Coating Science and Technology, 2015, Volume 2, No. 2

[21] Chen $X$, Zhou J, Wang $H, X u P, P a n ~ G . I n$ situ high temperature X-ray diffraction studies of ZnO thin film. Chinese Phys B 2011; 20: 096102. http://dx.doi.org/10.1088/1674-1056/20/9/096102
[22] Caglar $\mathrm{Y}$, llican S, Caglar M, et al. Influence of heat treatment on the nanocrystalline structure of $\mathrm{ZnO}$ film deposited on p-Si. J Alloys Compd 2009; 481: 885-9.

http://dx.doi.org/10.1016/i.jallcom.2009.03.140

(c) 2015 Pokharel et al.; Licensee Lifescience Global.

This is an open access article licensed under the terms of the Creative Commons Attribution Non-Commercial License (http://creativecommons.org/licenses/by-nc/3.0/) which permits unrestricted, non-commercial use, distribution and reproduction in any medium, provided the work is properly cited. 